\title{
Effect of Skater Exercise on Cardiopulmonary Fitness and Balance in Patients with Mild Chronic Stroke. - A Pilot Study -
}

\author{
Min-Su Kim \\ Department of Rehabilitation Medicine, School of Medicine, Wonkwang University, Iksan, Korea
}

Purpose: This study was conducted to investigate the effects of skater exercise on cardiopulmonary fitness and balance function in patients with mild chronic stroke.

Methods: A total of ten chronic stroke patients with mild neurologic deficits were recruited. The participants were divided into two groups, a skater exercise $(n=5)$ and a control group $(n=5)$. Skater exercise was performed by physical therapists in the experimental group, whereas patients in the control group conducted self-exercise. One session of the intervention was carried out for 30 minutes, three times per week for eight weeks. Cardiopulmonary function, falling index, and Euro-Quality of Life-5 Dimension (EQ-5D) were measured before and after the intervention.

Results: No side effects were reported during and after skater exercise intervention. The peak aerobic capacity, falling index, and EQ-5D improved significantly in the experimental group compared with the control group after eight weeks of skater exercise $(p=0.002$, $p=0.010$, and $p=0.006$ ). Significant relationships were identified between the change in $E Q-5 D$ and peak aerobic capacity (R2 $=0.75$, $p=0.002) /$ falling index $(R 2=0.65, p=0.002)$.

Conclusion: Skater exercise was an effective physical therapy to improve cardiopulmonary fitness and balance function in patients with mild chronic stroke.

Keywords: Stroke, Skating, Exercise test, Postural balance

서 론

뇌졸중은 성인에서 장애를 남기는 가장 흔한 질병 중 하나이며, 국 내 유병률은 인구 고령화로 인하여 매년 증가하는 추세이다.1 뇌졸중 후 환자에 따라 다양한 정도의 편마비, 보행장애, 실어증, 인지장애 등과 같은 신경학적 결손이 발생하며, 현재 병원에서 시행하는 재활 치료는 주로 중등도상의 기능장애가 있는 환자의 기능회복에 초점 을 맞추고 있다. 그러나 신경학적 손상이 비교적 경한 환자들은 전체 뇌졸중의 약 $50 \%$ 를 차지하며, 이들은 일상생활동작 수행과 보행에 는 문제가 없으나 발병전의 활동적인 운동을 수행할 때 어려움을 호 소한다. 특히 6 개월 이상의 만성기에 접어들면서 활동성 저하에 따 른 심폐기능 저하, 근력약화 등이 지속되면서 건강관련 삶의 만족도 가 정상인에 비해 크게 떨어지는 것으로 보고되었다. ${ }^{2}$ 그러나 이러한 문제가 있음에도 경증 만성 뇌졸중 환자들은 병원에서 적합한 재활 치료를 받기 보다 자가운동으로 대신하는 경우가 많다.

Received Sep 20, 2016 Revised Sep 23, 2016

Accepted Sep 26, 2016

Corresponding author Min-Su Kim

E-mail helmaine@naver.com
실제로 병원에서 수행되고 있는 신경학적 안정기에 접어든 만성기 뇌졸중 재활치료는 급성기에 비하여 제한적이다. 만성 뇌졸중 재활 치료는 주로 균형기능 증진에 초점이 맞추어져 있으며 고유수용성 신경근 촉진법을 이용한 체중지지 훈련, 가상현실 프로그램, 이중 운 동과제 훈련, 승마기구 운동 등은 환자의 이동성과 균형기능을 증진 시켰다고 보고되었다. ${ }^{3-6}$ 그러나 경증 만성 뇌졸중 환자들은 단순한 이동성 증진이 아닌 활동적인 스포츠를 할 수 있는 더 높은 수준의 심폐지구력과 균형기능 회복을 기대하며 이를 통해 건강에 대한 자 신감을 다시 찾기를 원한다. 일부 병원에서는 이러한 경증 만성 뇌졸 중 환자를 대상으로 일부 스포츠의학센터를 보유한 병원에서 운동 재활치료 경험이 풍부한 물리치료사를 통해 스포츠 운동치료 프로 그램을 운영하여 만족스러운 효과를 내고 있다. 그러나 이러한 스포 츠 운동치료의 경우 비용이 많이 소요되며 전문적인 스포츠의학센 터를 보유한 병원은 제한적이기 때문에 많은 병원에서 일반적으로 적용하기 어려운 점이 있다. 이러한 점을 고려할 때 스케이터 운동은

Copylight (C2016 The Korea Society of Physical Therapy

This is an Open Access article distribute under the terms of the Creative Commons Attribution Non-commercial License (Http:// creativecommons.org/license/by-nc/4.o.) which permits unrestricted non-commercial use, distribution, and reproduction in any medium, provided the original work is properly cited. 
스포츠 운동 프로그램에 비하여 더 많은 병원의 재활치료실에서 저 비용으로 적용될 수 있는 대안이 될 수 있다.

스케이터 운동은 스케이터 동작 패턴에 기반하여 교차훈련을 적 용한 고유수용성 신경근 촉진법의 치료 기법의 한 방법으로 근육과 건 내의 고유수용기를 자극함으로써 근력, 유연성, 협응 기능을 향상 시켜 뇌졸중 후 환자의 균형과 이동성을 증가시킨다고 보고된 바 있 다.7 그러나 스케이터 동작 패턴이 심폐 기능과 건강관련 삶의 질에 미치는 영향에 대해서는 현재 연구된바 없으며, 또한 본 연구의 스케 이터 운동 기법은 단순 이동성보다 더욱 적극적인 활동이 가능하도 록 심폐기능과 균형기능 향상에 초점을 맞추어 구성하였다. 따라서 본 연구에서는 스케이터 운동을 경증 만성 뇌졸중 환자에게 적용하 여 심폐기능과 균형기능에 미치는 치료적 효과를 알아보고, 이를 통 해 건강 관련 삶의 질을 증진시킬 수 있는지 조사하고자 하였다.

\section{연구 방법}

\section{1. 연구대상}

뇌졸중 발병 후 6개월 이상 경과하고, National institutes of health stroke scale (NIHSS) 2점 이하의 경증 만성 뇌졸중 환자를 연구 대상
으로 하였다. 대상자 중 한글판 간이정신상태검사(mini-mental status examination of Korean version, K-MMSE)상 26점 이하의 인지장애, 중 대한 심혈관계, 정신질환, 근골격계 질병이 동반된 환자는 제외하였 다. 대상자는 두 군으로 나누어 병원 재활치료실에서 외래기반으로 스케이터 운동 치료를 받은 실험군과 물리치료 없이 수영, 조깅 등과 같은 자가운동을 한 대조군으로 나누었다. 대상자들의 나이, 성별, 발 병 후 치료시작 전까지의 기간, 뇌졸중 종류, K-MMSE, NIHSS 등 결 과지표에 영향을 줄 수 있는 기저항목들을 조사하여 비교 분석하였 다. 모든 환자에 대하여 연구 과정에 대한 동의서를 받았으며, 본 연 구는 연구수행병원 기관윤리심의위원회의 승인을 받았다.

\section{2. 실험방법}

\section{1) 스케이터 운동 프로토콜}

기본 스케이터 운동 동작은 기립 자세에서 양다리를 지면에 붙인 닫힌 사슬 동작으로 시행하였다. 시작 전 수분간 정확한 자세를 잡을 수 있도록 천천히 준비운동을 시행하였다. 우측으로 스텝을 옮겨 체 중을 부하하면서 좌측 팔은 몸을 가로지르게 이동하는 스케이터 동 작을 좌우로 한번씩 번갈아 가며 시행했을 때 1회로 하였다(Figure 1). 환자의 근력, 심폐기능, 균형기능 등 뇌졸중 후 기능 상태에 따라 이동
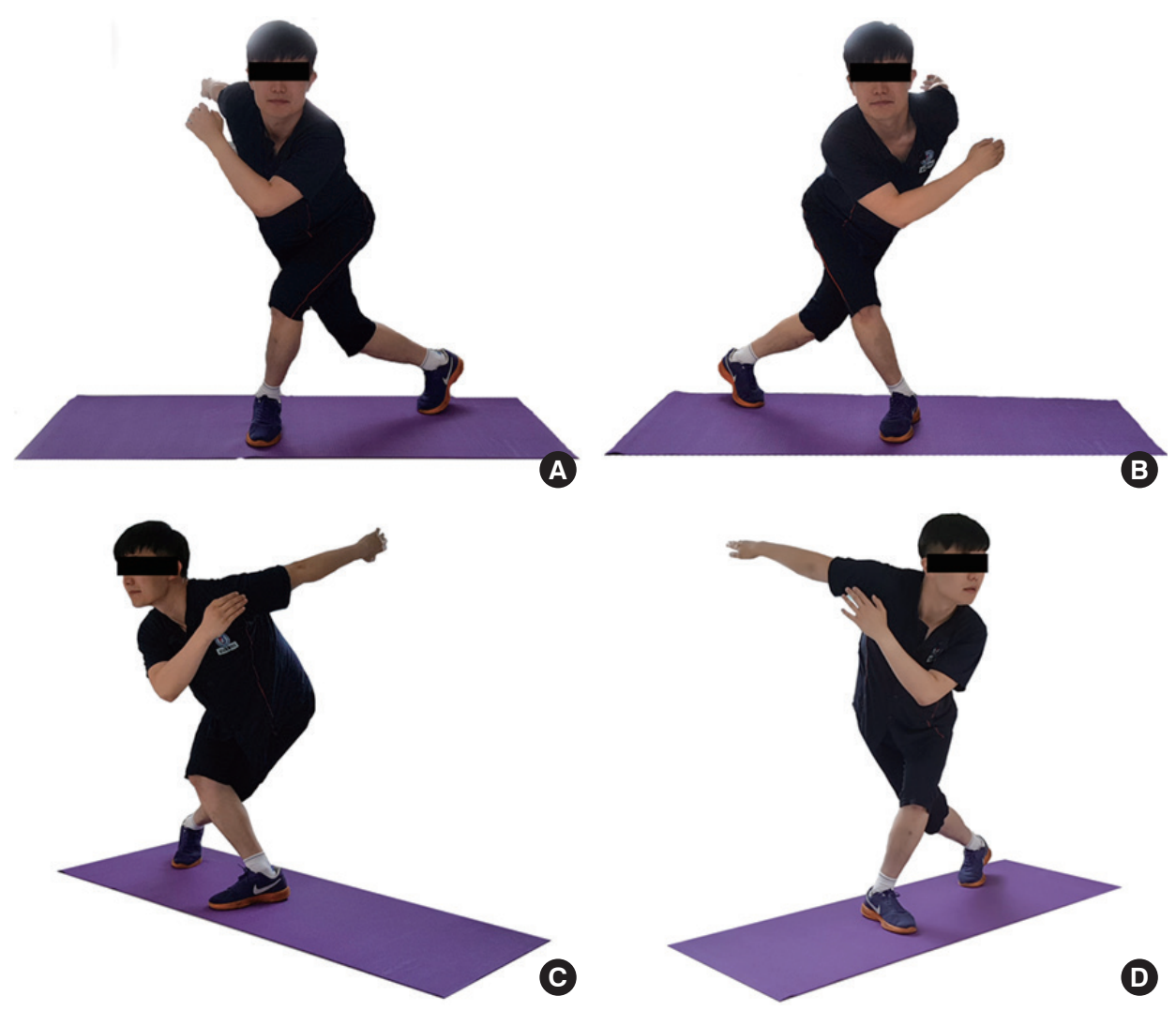

Figure 1. Basic motions of skater exercise. (A) Start standing on one leg (unaffected side). Hop from side to side, switching legs similar to speed skating. Swing arms side to side with lowering body down. (B) Reverse direction by jumping to the other side with opposite leg, and continue alternating sides. (C) View from the right. (D) View from the left. 
속도, 스텝의 크기, 체중 부하 정도를 달리하면서 진행하였다. 강도는 점진적으로 증가시키면서 Borg rating of perceived exertion scale (RPE) 15 점 미만이 되도록 조절하면서 수행하였다. 1세트는 20회 수행하였 으며, 1 세트 후 1 분간 휴식하며 전신 스트레칭 운동을 병행하였다. 효 과적인 운동치료를 위하여 기본 5세트 시행 후 스케이터 스텝 동작 이 외에 점프 동작(small or big skater jumps), 자세를 바꾸는 점프동작(rotational skater jump), 런지(skater lunge), 스케이터 스쿼트(skater squat), 밴드를 이용한 동작(band resisted skater jump), 경사판을 이용한 동작 (slant board), 가벼운 덤벨이나 볼을 이용한 무게 부하 동작(weighted skater jump) 등의 복합 스케이터 운동을 3-5세트씩 환자에 따라 적절 히 포함하여 치료를 시행하였다. 환자는 담당 물리치료사에 의하여 스케이터 운동을 하루 30 분씩, 주 3 회, 총 8 주간 시행 받았다.

\section{2) 치료효과의 평가}

(1) 심폐기능

심폐기능은 수정된 브루스 프로토콜(modified Bruce protocol)을 이용하여 트레드밀 기반 운동부하검사 및 호흡가스분석을 통해 평 가하였다. 검사 기기는 12 채널 실시간 운동부하검사용 심전도 검사 기(Quinton Q-stress, Mortara Instrument, INC, USA)와 운동부하검사 용 트레드밀(Q-stress TM55, Mortara Instrument, INC, USA), 자동 혈 압 및 맥박 측정기(247BP, SunTech Medical, USA), 호흡가스 분석기 (TrueOne 2,400, ParvoMedics, INC, USA)를 사용하였다. 본 검사를 통 해 산소용량(aerobic capacity), 심혈관반응(cardiovascular response), 호 흡환기반응(ventilator response)으로 나누어 심폐기능변화를 조사하 였다. 산소용량은 최고산소용량 $\left(p e a k \mathrm{VO}_{2}\right)$ 을 확인하고 심혈관반응 은 최고 운동시 산소맥박(oxygen pulse), 수축기 및 이완기 혈압, 휴지 기 및 최고 운동시의 심박수를 평가하였다. 또한 호흡환기반응은 최 고 운동시 분당 환기량(minute ventilation, $\mathrm{VE}$ )과 환기효율(ventilatory efficiency, $\mathrm{VE} / \mathrm{VCO}_{2}$ )을 각각 측정하였다.

\section{(2) 균형기능}

균형기능은 Tetrax posturography (Sunlight Medical Ltd., Ramat Gan, Israel)를 이용하여 정량적으로 측정하였다. Tetrax는 4 개의 각각 독립 된 힘판을 통해 자세 흔들림을 분석하여 다양한 균형 관련 지수들을 산출할 수 있다. ${ }^{8}$ 검사 시 좌우 전족부와 후족부를 각각의 힘판 위에 놓고 기립한 상태에서 시각이나 체성 감각을 차단하거나 다양하게 자세를 변화시키면서 균형을 평가한다. 본 검사를 통하여 낙상 지수 (falling index, FI)와 안정성 지수(stability index, SI)를 평가하였다. FI는 SI를 기반으로 하여 낙상의 위험도를 나타내는 지표이며, SI는 힘판의 변화에 따라 피험자가 최대한 안정화된 상태로 자세를 적응하고자 하는 능력을 반영한다. 이에 따른 체중 부하 변화의 빈도를 측정하기
때문에 더 높은 점수는 균형기능이 떨어진 상태로 볼 수 있다.

\section{(3) 건강관련 삶의 질}

스케이터 운동 전후 건강관련 삶의 질의 변화를 확인하기 위하여 Euro-Quality of Life-5 Dimension (EQ-5D)을 이용하여 평가하였다. EQ-5D는 이동능력(mobility), 자기관리(self-care), 일상생활 활동(usual activity), 통증/불편감(pain/discomfort), 불안/우울(anxiety/depression) 을 3 단계로 측정하는 5 가지 문항으로 구성되어 있으며, 뇌졸중 환자 에서 높은 응답률과 유효성이 검증된 도구이다. 또한 본 연구의 일차 결과 지표인 최고산소용량 및 낙상지수의 변화 정도와 건강관련 삶 의 질 변화 정도가 연관성이 있는지에 대해서도 아울러 분석하였다.

\section{3) 통계분석}

스케이터 운동을 받은 실험군과 대조군 간의 기저 요인 간의 차이 가 있는지 확인하기 위하여 연속변수는 Mann Whitney U-test, 명목 변수는 Fisher's exact test를 이용하였다. 중재 전후 각 결과지표에서 유 의한 변화가 있는지 알아보기 위하여 Wilcoxon signed ranked test를 이용하였으며 두 군간의 결과지표의 변화 정도가 차이를 확인하기 위하여 Mann Whitney U-test를 사용하였다. 최고산소용량과 낙상지 수 변화 정도와 EQ-5D의 관련성을 조사하기 위하여 Spearman correlation analysis를 이용하였다. 본 연구에서 수집된 데이터는 SPSS 19.4 (IBM Co., Armonk, NY, USA)을 이용하여 분석하였으며, 통계적 유의 수준은 $\mathrm{p}<0.05$ 로 설정하였다.

\section{결 과}

\section{1. 연구 대상자의 특성}

총 10 명의 경증 만성 뇌졸중 환자를 대상으로 예비 연구를 수행하

Table 1. Clinical characteristics of the participants

\begin{tabular}{lccc}
\hline & Skater $(\mathrm{n}=5)$ & Control $(\mathrm{n}=5)$ & $\mathrm{p}$-value \\
\hline Age (yr) & $52.4 \pm 5.4$ & $48.6 \pm 4.1$ & 0.310 \\
Sex (M:F), $\mathrm{n}(\%)$ & & & 1.000 \\
$\quad$ Male, $\mathrm{n}(\%)$ & $3(60.0)$ & $2(40.0)$ & \\
$\quad$ Female, $\mathrm{n}(\%)$ & $2(40.0)$ & $3(60.0)$ & \\
Time from the onset (mo) & $9.6 \pm 1.1$ & $8.8 \pm 0.8$ & 0.310 \\
Stroke type & & & 1.000 \\
$\quad$ Infarct, $\mathrm{n}(\%)$ & $2(40.0)$ & $3(60.0)$ & \\
Hemorrhage, $\mathrm{n}(\%)$ & $3(60.0)$ & $2(40.0)$ & \\
K-MMSE & $29.4 \pm 0.9$ & $29.6 \pm 0.5$ & 0.841 \\
NIHSS & $1.0 \pm 0.7$ & $0.8 \pm 0.8$ & 0.690 \\
\hline
\end{tabular}

Values are presented as mean \pm standard deviation. K-MMSE: mini-mental status examination of Korean version, NIHSS: national institutes of health stroke scale. 
였으며, 각각 5 명씩 실험군과 대조군으로 분류되었다. 모든 환자들은 안전하게 스케이터 운동을 진행하였으며 치료 도중 및 치료 종결 후 통증, 부종, 염좌 등의 근골격계 부작용과 어지럼증, 두통, 근위약 등 의 뇌신경학적 부작용 증상을 호소하는 환자는 관찰되지 않았다. 대 상자의 나이, 성별, 발병 후 중재 전까지의 기간, 뇌졸중 종류, $\mathrm{K}$ MMSE, NIHSS에서 두 군 간의 차이는 관찰되지 않았다(Table 1).

\section{2. 심폐기능에 대한 효과}

8 주간의 스케이터 운동치료 후 최고산소용량은 평균 $18.5 \pm 1.2$ 에 서 $19.9 \pm 1.4 \mathrm{~mL} / \mathrm{kg} / \mathrm{min}$ 로 실험군에서 유의한 향상이 관찰되었다
( $\mathrm{p}=0.020)$ (Table 2). 대조군에서 실험 전후 최고산소용량, 산소맥박, 수축기 및 이완기 혈압, 심박수, 분당 환기량 및 환기 효율에 유의한 차이가 관찰되지는 않았다. 또한 두 군간의 증가 호전 정도를 비교했 을 때 최고산소용량 증가 정도는 실험군이 대조군에 비하여 유의한 호전이 확인되었다 $(\mathrm{p}=0.002)$.

\section{3. 균형기능에 대한 효과}

균형 기능 평가 시 낙상 지수는 실험군에서 $44.6 \pm 3.8$ 에서 $30.1 \pm 4.7$ 으로 스케이터 운동치료 후 유의하게 감소하였다 $(\mathrm{p}=0.032)$ (Table 3). 또한 실험군에서는 안정성 지수 또한 전 검사 지표에서 유의한 향상

Table 2. Comparison of the effects to cardiopulmonary fitness between skater exercise and control group

\begin{tabular}{|c|c|c|c|c|c|}
\hline & \multicolumn{2}{|c|}{ Skater exercise } & \multicolumn{2}{|c|}{ Control } & \multirow{2}{*}{$p$-value } \\
\hline & Pre & Post $^{a}$ & Pre & Post $^{2}$ & \\
\hline Peak VO $2, \mathrm{~mL} / \mathrm{kg} / \mathrm{min}$ & $18.5 \pm 1.2$ & $19.9 \pm 1.4^{\star}$ & $18.3 \pm 2.0$ & $18.5 \pm 2.9$ & $0.002^{*}$ \\
\hline Peak $\mathrm{O}_{2}$ pulse, $\mathrm{mL} /$ beat & $8.9 \pm 0.4$ & $8.9 \pm 0.6$ & $9.2 \pm 0.8$ & $9.0 \pm 0.9$ & 0.225 \\
\hline SBP peak exercise, $\mathrm{mmHg}$ & $150.2 \pm 8.4$ & $149.4 \pm 5.4$ & $144.5 \pm 9.2$ & $147.0 \pm 10.2$ & 0.416 \\
\hline DBP peak exercise, $\mathrm{mmHg}$ & $81.5 \pm 6.5$ & $81.2 \pm 4.0$ & $83.0 \pm 5.5$ & $82.2 \pm 4.6$ & 0.480 \\
\hline HR at rest, bpm & $68.8 \pm 7.5$ & $66.4 \pm 4.0$ & $70.2 \pm 8.4$ & $71.4 \pm 6.6$ & 0.510 \\
\hline HR at peak exercise, bpm & $128.0 \pm 6.6$ & $131.2 \pm 6.8$ & $130.2 \pm 13.4$ & $128.4 \pm 10.4$ & 0.783 \\
\hline$V_{E}$ peak exercise, L/min & $47.9 \pm 6.1$ & $47.5 \pm 5.3$ & $46.8 \pm 7.4$ & $48.4 \pm 9.2$ & 0.345 \\
\hline$V_{E}$ versus $V_{C O}$ slope & $26.1 \pm 1.0$ & $26.8 \pm 0.9$ & $27.2 \pm 2.7$ & $26.8 \pm 2.2$ & 0.223 \\
\hline RER peak exercise & $1.04 \pm 0.01$ & $1.03 \pm 0.01$ & $1.02 \pm 0.02$ & $1.02 \pm 0.01$ & 0.520 \\
\hline RPE peak exercise & $14.6 \pm 0.7$ & $14.8 \pm 0.7$ & $14.2 \pm 1.0$ & $14.8 \pm 0.6$ & 0.328 \\
\hline
\end{tabular}

Values are presented as mean \pm standard deviation.

$\mathrm{VO}_{2}$ : oxygen consumption, bpm: beat per minute, SBP: systolic blood pressure, DBP: diastolic blood pressure, $\mathrm{V}_{\mathrm{E}}$ : minute ventilation, $\mathrm{VCO}_{2}$ : carbon dioxide consumption, RER: respiratory exchange ratio, RPE: rate of perceived exertion.

aWilcoxon signed ranked test.

${ }^{b}$ Mann Whitney U-test.

${ }^{*} \mathrm{p}<0.05$.

Table 3. Comparison of the effects to balance function in various position using Tetrax posturography between skater exercise and control group

\begin{tabular}{|c|c|c|c|c|c|}
\hline & \multicolumn{2}{|c|}{ Skater exercise } & \multicolumn{2}{|c|}{ Control } & \multirow{2}{*}{$p$-value } \\
\hline & Pre & Post ${ }^{3}$ & Pre & Post ${ }^{a}$ & \\
\hline Falling index (Fl) & $44.6 \pm 3.8$ & $30.0 \pm 4.7^{\star}$ & $39.8 \pm 4.2$ & $38.4 \pm 4.9$ & $0.010^{*}$ \\
\hline \multicolumn{6}{|l|}{ Stability index (SI) } \\
\hline NO & $28.0 \pm 3.6$ & $15.0 \pm 1.0^{*}$ & $30.1 \pm 4.9$ & $26.8 \pm 3.8$ & $0.021^{*}$ \\
\hline NC & $27.2 \pm 3.4$ & $15.8 \pm 1.6^{*}$ & $26.4 \pm 4.1$ & $25.0 \pm 3.1$ & $0.010^{*}$ \\
\hline $\mathrm{PO}$ & $30.7 \pm 2.9$ & $17.8 \pm 1.8^{*}$ & $28.8 \pm 1.9$ & $27.2 \pm 2.1$ & $0.010^{*}$ \\
\hline PC & $28.2 \pm 1.9$ & $15.6 \pm 0.9^{\star}$ & $28.4 \pm 2.2$ & $26.8 \pm 3.0$ & $0.010^{*}$ \\
\hline $\mathrm{HR}$ & $27.4 \pm 2.0$ & $17.4 \pm 1.4^{*}$ & $27.2 \pm 3.0$ & $26.4 \pm 2.2$ & $0.010^{*}$ \\
\hline $\mathrm{HL}$ & $27.8 \pm 1.7$ & $16.4 \pm 1.5^{\star}$ & $26.8 \pm 2.1$ & $26.4 \pm 1.5$ & $0.010^{*}$ \\
\hline$H B$ & $29.0 \pm 2.1$ & $20.8 \pm 1.7^{*}$ & $28.6 \pm 1.4$ & $27.4 \pm 2.0$ & $0.021^{*}$ \\
\hline $\mathrm{HF}$ & $23.2 \pm 1.2$ & $14.2 \pm 1.0^{*}$ & $22.6 \pm 1.0$ & $21.0 \pm 1.0$ & $0.010^{*}$ \\
\hline
\end{tabular}

Values are presented as mean \pm standard deviation.

NO: standing with eyes open, NC: standing with eyed closed, PO: standing on pillow with eyes open, PC: standing on pillow with eyes closed, HR: standing with eyes closed with head rotation to the right side, HL: standing with eyes closed with head rotation to the left side, HB: standing with eyes closed with neck extension, HF: standing with eyes closed with neck flexion.

ailcoxon signed ranked test.

${ }^{b}$ Mann Whitney U-test.

$* \mathrm{p}<0.05$. 

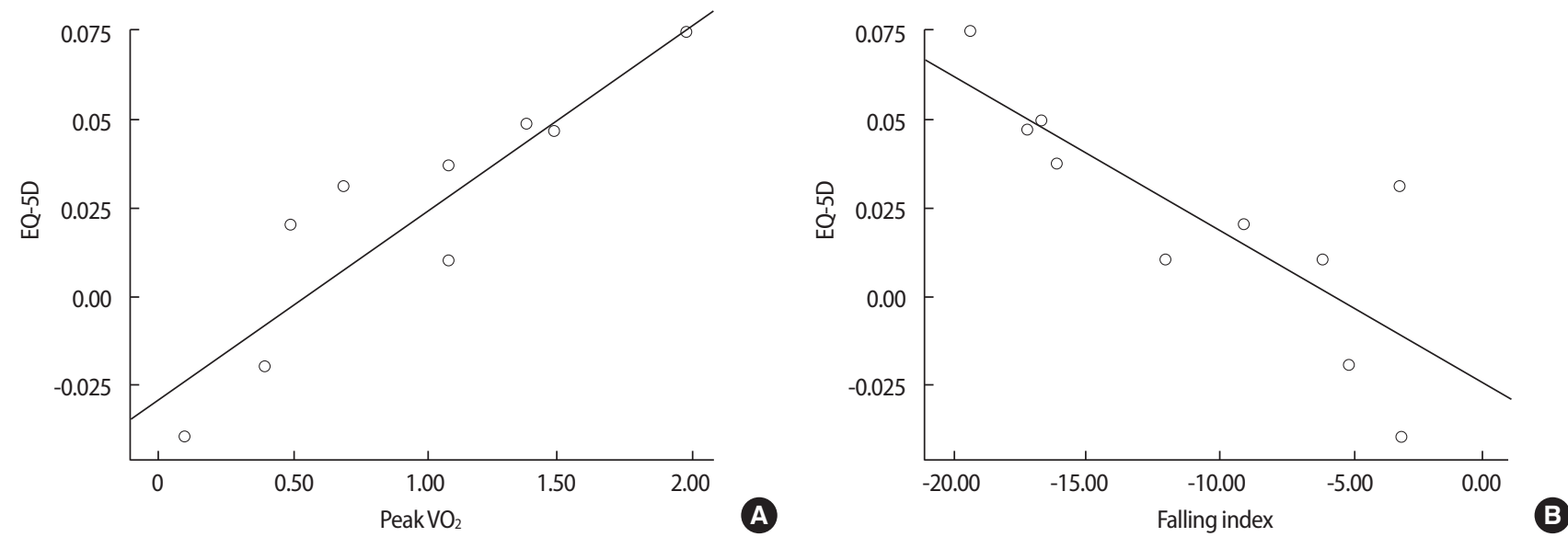

Figure 2. Relationship between EQ-5D and primary outcome measures. (A) Peak aerobic capacity $\left(R^{2}=0.75, p=0.002\right)$. (B) Falling index $\left(R^{2}=0.65\right.$, $p=0.002$ ).

이 확인되었다. 그러나 대조군에서 실험 전후 낙상지수와 안정성 지 수 항목에서는 모두 유의미한 변화가 관찰되지 않았다. 두 군 간의 변 화 정도를 비교하였을 때 스케이터 운동 치료를 받은 환자에서 낙상 위험도는 대조군과 비교하여 유의하게 감소하였다 $(\mathrm{p}=0.010)$.

\section{4. 건강관련 삶의 질에 대한 효과와 관련성 분석}

$\mathrm{EQ}-5 \mathrm{D}$ 는 실험군에서 운동 치료 전 $0.88 \pm 0.03$ 에서 $0.92 \pm 0.02$ 으로 통계적으로 유의한 향상이 이루어 졌으나 $(\mathrm{p}=0.010)$, 대조군은 $0.88 \pm$ 0.04 에서 $0.87 \pm 0.06$ 으로 소폭 감소하는 경향을 보였다. EQ-5D의 8 주 간의 중재 후 변화 정도는 두 군 간에 유의한 차이가 관찰되었다 $(\mathrm{p}=0.006)$.

최고산소용량 변화량과 $\mathrm{EQ}-5 \mathrm{D}$ 의 변화 정도를 연관 분석을 시행 한 결과 서로 유의한 상관관계가 관찰되었으며 $\left(\mathrm{R}^{2}=0.75, \mathrm{p}=0.002\right)$ (Figure 2A), 또한 낙상 지수의 감소 정도와도 유의한 연관성이 확인되 었다 $\left(\mathrm{R}^{2}=0.65, \mathrm{p}=0.002\right)$ (Figure $\left.2 \mathrm{~B}\right)$.

\section{고 찰}

본 연구 목적은 신경학적으로 안정기에 있는 경증 만성 뇌졸중 환 자에게 스케이터 운동치료를 시행하여 심폐기능, 균형기능, 건강 관 련 삶의 질에 미치는 영향을 조사하는 것이다. 스케이터 동작은 고유 수용성 신경근 촉진법의 개별 패턴을 통합한 동작으로 대상자의 능 동적인 운동 참여를 유도하고 근력과 체간 안정성을 향상시킨다고 알려져 있다.69 특히 뇌졸중 환자들을 대상으로 스케이터 동작 패턴 은 뇌졸중 환자들에서 균형과 이동성을 증가시켰다는 연구 결과가 보고되었으나, 심폐기능에 미치는 효과에 대한 연구는 부족한 상태 이다. 실제 스케이터 동작은 효과적인 유산소 운동으로 잘 알려져 있 어 일반 피트니스 센터에서도 수행되고 있으며, 정상인을 대상으로
시행된 연구에서 최대 산소용량이 증가하였다고 보고된 바 있다. ${ }^{10,11}$ 심폐 기능은 주로 뇌졸중 발병 6-12개월 때에 저하된다고 알려져 있 으며, 이는 만성기에 건강관련 삶의 질을 떨어뜨리기 때문에 이에 대 한 치료는 중요하다. ${ }^{12}$ 특히 경증 만성 뇌졸중 환자는 일상생활동작 이 필요한 정도의 최고산소용량 이상의 활동적 기능 수준까지 회복 을 기대하나 의료진은 주로 신경학적 손상에만 초점을 맞추어 치료 하는 경우가 많다. 이러한 점에서 스케이터 운동은 경증 만성 뇌졸중 환자에게 심폐기능 향상을 돕고, 이를 통해 건강관련 삶의 질이 증진 시킬 수 있는 재활치료임을 확인하였다.

아급성기 뇌졸중 재활 치료에도 트레드밀, 상지 및 하지 에르고미 터를 이용한 약한 강도의 유산소 운동은 기능 회복을 위하여 기본적 으로 포함되어 있으며, ${ }^{13}$ 만성기 재활치료에 더욱 적극적으로 이루어 져야 한다. 이러한 최고산소용량 증진은 뇌졸중 후 운동 기능 회복 외 에도 인지 기능 회복에도 중요한 영향을 주어 뇌졸중 후 기능 회복에 큰 역할을 한다. ${ }^{4}$ 인라인스케이트는 최대하 운동 부하 수준으로 운동 할 경우에도 매우 효과적인 유산소 운동으로 알려져 있으며, ${ }^{10}$ 팔을 반복적으로 교대로 스윙 하는 동작은 그 효과를 배가시킨다..$^{15}$ 본 연 구 결과 8 주간 치료 후 일차 지표인 최고산소용량은 유의하게 증가하 였으며, 스케이터 운동으로 충분한 유산소 운동 효과를 갖고 있음을 확인하였다. 대조군에서는 최고 산소용량에는 변화가 없었으며, 일부 환자에서는 오히려 감소하는 경향을 보였다. 대조군과 실험군 모두 다 른 산소맥박 등의 심혈관계반응과 환기량 등의 호흡환기 반응 지표에 는 유의한 차이가 관찰되지 않았다. 이는 이러한 심폐기능의 전반적 인 향상을 이루기 위해서는 장기간 꾸준한 운동치료가 필요하다는 점에 기인했다고 생각된다. 다른 연구에서도 중재 기간이 짧을 경우 심폐기능은 향상이 다소 부족할 수 있다는 점을 보여준 바 있다. ${ }^{12}$ 따 라서 스케이터 운동이 심폐 기능에 미치는 장기적인 효과를 더욱 정 확하게 파악하기 위해서는 차후 추가적인 연구가 필요하다. 
본 연구에서 스케이터 운동치료 후 균형기능 평가에서도 대조군 에 비하여 유의한 향상이 관찰되었다. 뇌졸중 후 균형장애는 전체 환 자의 $73 \%$ 에서 관찰될 정도로 흔하며, 장기적인 예후에 중대한 영향 을 준다. ${ }^{16}$ 또한 균형감각저하는 평지 보행 시 낙상과 같은 문제 외에 도 적극적인 활동을 수행하는데 큰 장해가 된다. 스케이터 동작은 근 력과 균형감각발달을 위하여 어린이에게 권유되고 있으며, ${ }^{17}$ 노인에 게서도 낙상 방지 등을 위한 균형 조절 기능 향상을 위한 목적으로 도 추천되고 있다. ${ }^{18}$ 또한 최근 뇌성마비와 자폐 환자들을 대상으로 재활치료 목적으로 스케이터 운동을 시행한 결과 균형감각향상이 이루어졌으며, 이를 통해 전체적인 기능 향상에도 기여했다는 연구 들이 나와 있다. ${ }^{19,20}$ 이는 스케이터 패턴(skater pattern)은 가장 효율적 이고 기능적인 동작을 가장 잘 표현한 것이며, 패턴의 결합을 이용하 는 것은 체간의 안정성을 향상 시키고 사지의 고유수용성감각을 증 진시킬 수 있는 점이 기여한 것으로 생각된다.

뇌졸중 후 건강 관련 삶의 질은 신경학적 손상이나 우울증 등과 같 은 정서적 요인 등 여러 가지 요인이 관여한다. ${ }^{21}$ 그러나 최근 뇌졸중 후 건강관련 삶의 질은 발병 전에 비해 저하되며 심폐기능저하와 균형 기능저하가 중요한 역할을 한다 점이 부각되고 있다. ${ }^{22,23}$ 본 연구 대상 자도 실험군과 대조군 모두 중재 연구 시작 전에 전체적인 $\mathrm{EQ}-5 \mathrm{D}$ 평 균은 $0.88 \pm 0.03$ 으로 정상 성인 평균인 0.96 점에 비해 건강관련 삶의 질이 상당히 저하되어 있는 상태였다. 그러나 스케이터 운동을 수행 한 군에서 치료 후 EQ-5D는 유의하게 증가하였으며, 대조군은 유의 한 변화가 관찰되지 않았다. 이에 대한 원인을 분석하기 위하여 연관 분석을 시행하였으며, 건강관련 삶의 질의 향상 정도는 최고산소용량 과 균형기능향상 정도와 유의한 상관 관계가 있었다. 따라서 스케이 터 운동 치료는 경증 만성 뇌졸중 환자에게 활동성을 더욱 증진시킴 으로써 건강에 대한 자신감을 회복하고 건강 관련 삶의 질을 향상에 도 기여하였음을 증진시키는데 기여하였음을 확인하였다.

경증 만성 뇌졸중 환자를 대상으로 수행한 본 연구는 몇 가지 제 한점이 있다. 본 연구는 예비 연구로서 연구 대상자가 10 명으로 적으 며, 재활 치료 기간이 8 주로서 심폐 기능과 균형감각 기능을 더욱 효 과적으로 향상시키기에 다소 짧을 수도 있다. 또한 치료 종결 후 심폐 기능, 균형기능 및 건강관련 삶의 질 지표가 장기적으로 지속되는지 에 대해 조사하지는 않았다. 이러한 제한점은 더 많은 연구 참여자를 대상으로 장기적인 추적 관찰을 포함한, 향후 추가 연구를 통해 보완 되어야 할 점으로 생각된다.

결론적으로 스케이터 운동치료는 재활치료실에서 물리치료사에 의해 쉽게 치료의 한 방법으로 수행될 수 있으며, 경증 만성 뇌졸중 환자들에게 안전하게 심폐 기능과 균형감각 기능 호전에 도움이 되 었다. 이는 더욱 활동적인 일상 생활을 가능하게 하여 건강관련 삶의 질을 높여주었다. 따라서 경증 만성 뇌졸중 환자들에게 뇌졸중 재활
프로그램으로 스케이터 운동치료를 포함하는 것은 재활치료실의 물 리치료사에게 추천된다.

\section{Acknowledgements}

이 논문은 2016년도 원광임상의학연구소 연구비 지원에 의해 이 루어졌음

\section{참고문헌}

1. Hong KS, Bang OY, Kang DW et al. Stroke statistics in Korea: Part I. Epidemiology and risk factors: a report from the Korean stroke society and clinical research center for stroke. J Stroke. 2013;15(1):2-20.

2. Chang WH, Sohn MK, Lee J et al. Korean stroke cohort for functioning and rehabilitation (KOSCO): study rationale and protocol of a multicentre prospective cohort study. BMC Neurol. 2015;15:42.

3. Cho GH, Lee WH. The effects of two motor dual task training on balance and gait in patients with chronic stroke. J Kor Phys Ther. 2010; 22(4):7-14.

4. Choi AY, Cho OS. The effects of mechanical horseback riding exercise on the dynamic balance in patients with cerebral infarction. J Kor Phys Ther. 2014;26(2):123-9.

5. Kim JH, Kim JS. Effects of virtual reality program on standing balance in chronic stroke patients. J Kor Phys Ther. 2005;17(3):351-67.

6. Lee JS, Nam GW, Kim KY, et al. Effect of weight bearing exercise on weight bearing and balance for patients with chronic stroke. J Kor Phys Ther. 2012;24(4):253-61.

7. Lim CG. The effects of proprioceptive neuromuscular facilitation (PNF) pattern exercise using the sprinter and the skater on balance and gait function in the stroke patients. J Kor Phys Ther. 2014;26(4):249-56.

8. Yi TI, Kang Y, Lee YS. Reliability of single leg balance test using posturography. Korean J Sports Med. 2014;32(2):120-5.

9. Kim DK. Change of walking and stair up in hemiplegia by proprioceptive neuromuscular facilitation techniques. J Kor Phys Ther. 1999; 11(3):57-64.

10. CHO SB. The effect of cardiorespiratory function of the off-seasons inline skating training program. Journal of Korea Sport Research. 2005; 16(3):117-24.

11. Wallick ME, Porcari JP, Wallick SB, et al. Physiological responses to inline skating compared to treadmill running. Med Sci Sports Exerc. 1995; 27(2):242-8.

12. Yoon MR, Choi HS, Shin WS. Effects of the abdominal drawing-in maneuver and the abdominal expansion maneuver on grip strength, balance and pulmonary function in stroke patient. J Kor Phys Ther. 2015; 27(2):147-53.

13. Pang MY, Eng JJ, Dawson AS, et al. The use of aerobic exercise training in improving aerobic capacity in individuals with stroke: a meta-analysis. Clin Rehabil. 2006;20(2):97-111.

14. Moriya M, Aoki C, Sakatani K. Effects of physical exercise on working memory and prefrontal cortex function in post-stroke patients. Adv Exp Med Biol. 2016;923:203-8. 
15. Hegge AM, Ettema G, de Koning JJ, et al. The effects of the arm swing on biomechanical and physiological aspects of roller ski skating. Hum Mov Sci. 2014;36:1-11.

16. Kwon MJ. The fall circumstance and related factors associated with fall in the stroke patients. J Kor Phys Ther. 2008;20(3):19-28.

17. Muehlbauer T, Kuehnen M, Granacher U. Inline skating for balance and strength promotion in children during physical education. Percept Mot Skills. 2013;117(3):665-81.

18. Lamoth CJ, van Heuvelen MJ. Sports activities are reflected in the local stability and regularity of body sway: older ice-skaters have better postural control than inactive elderly. Gait Posture. 2012;35(3):489-93.

19. Walsh SF, Scharf MG. Effects of a recreational ice skating program on the functional mobility of a child with cerebral palsy. Physiother Theory Pract.
2014;30(3):189-95.

20. Casey AF, Quenneville-Himbeault G, Normore A, et al. A therapeutic skating intervention for children with autism spectrum disorder. Pediatr Phys Ther. 2015;27(2):170-7.

21. Kwon MJ. Daily physical functioning and quality of life for stroke. J Kor Phys Ther. 2007;19(2):87-96.

22. Billinger SA, Arena R, Bernhardt J et al. Physical activity and exercise recommendations for stroke survivors: a statement for healthcare professionals from the American Heart Association/American Stroke Association. Stroke. 2014;45(8):2532-53.

23. Schmid AA, Van Puymbroeck M, Altenburger PA et al. Balance is associated with quality of life in chronic stroke. Top Stroke Rehabil. 2013; 20(4):340-6. 